\title{
RIO, CIDADE-CAPITAL E A EXPANSÃO DO ENSINO SECUNDÁRIO (1940-1960)
}

\author{
Patrícia Coelho da Costa (PUC-Rio)* \\ https://orcid.org/0000-0002-2277-2779 \\ Jefferson da Costa Soares (PUC-Rio)** \\ http://orcid.org/0000-0001-6959-3471
}

\section{RESUMO}

Este artigo apresenta um recorte analítico sobre a expansão do ensino secundário no Distrito Federal, entre os anos 1940 e 1960. A partir dos aspectos que caracterizaram a "capitalidade" do município do Rio de Janeiro neste período, as análises aqui propostas privilegiaram as relações centro-periferia. 0 estudo relacionou o processo de metropolização com a expansão do ensino secundário, com o objetivo de compreender como a nova organização do espaço dessa cidade influenciou a distribuição das oportunidades educacionais aos seus moradores. A pesquisa de natureza qualitativa utilizou como metodologia a interpretação de dados estatísticos entrecruzados com informações sobre os bairros cariocas publicadas em periódicos de grande circulação. Foi possível concluir que a expansão do ensino secundário carioca obedeceu a mesma lógica do capital imobiliário, que atendeu aos moradores dos bairros com maior poder aquisitivo, e restringiu as oportunidades de escolarização secundária para os residentes dos distritos mais distantes e pobres da cidade, reforçando a desigualdade social. Palavras-chave: Distrito Federal. Expansão do ensino secundário. Capitalidade.

\section{ABSTRACT}

\section{RIO, CAPITAL CITY AND THE EXPANSION OF HIGH SCHOOL (1940-1960)}

This article presents an analytical overview of the expansion of high school in Rio de Janeiro, between the years 1940 and 1960. Based on the aspects that characterized the capitality of this city in this period, the analyses proposed here favored the center-periphery relations. The study related the process of metropolization with the expansion of secondary education, with the objective of understanding how the new organization of the space influenced the distribution of educational opportunities to its residents. The qualitative research used as methodology the interpretation of statistical data crossed with information about the districts of Rio de Janeiro published in journals of great circulation.

* Doutora em Educação pela Universidade de São Paulo (USP). Professora Adjunta do Departamento de Educação da Pontifícia Universidade Católica do Rio de Janeiro (PUC-Rio). E-mail: pcoelho@puc-rio.br

* Doutor em Educação pela Pontifícia Universidade Católica do Rio de Janeiro (PUC-Rio). Professor Assistente do Departamento de Educação da Pontifícia Universidade Católica do Rio de Janeiro (PUC-Rio). E-mail: jefics@puc-rio.br 
It was possible to conclude that the expansion of secondary education in Rio followed the same logic as real estate capital, which served the residents of neighborhoods with greater purchasing power, and restricted the opportunities for secondary schooling for residents of the most distant and poor districts of the city, contributing to social inequality.

Keywords: Distrito Federal. Expansion of high school. Capitality.

\section{RESUMEM \\ RIO, CIUDAD CAPITAL Y LA EXPANSIÓN DE LA ESCUELA SECUNDARIA (1940-1960)}

Este artículo presenta una visión analítica de la expansión de la escuela secundaria en Río de Janeiro, entre los años 1940 y 1960. Basándose en los aspectos que caracterizaron la capitalidad de esta ciudad en este período, los análisis propuestos aquí favorecieron las relaciones centro-periferia. El estudio relacionó el proceso de metropolización con la expansión de la educación secundaria, con el objetivo de entender cómo la nueva organización del espacio influyó en la distribución de oportunidades educativas a sus residentes. La investigación cualitativa utilizó como metodología la interpretación de datos estadísticos cruzada con información sobre los distritos de Río de Janeiro publicada en revistas de gran circulación. Fue posible concluir que la expansión de la educación secundaria en Río siguió la misma lógica que el capital inmobiliario, que servía a los residentes de los barrios con mayor poder adquisitivo, y restringía las oportunidades de educación secundaria para los residentes de los distritos más distantes y pobres de la ciudad, contribuyendo a la desigualdad social.

Palabras clave: Distrito Federal. Expansión de la escuela secundaria. Capitalidad.

\section{Rio de Janeiro, sua \\ "capitalidade" e o ensino secundário}

A partir dos anos 1930, houve o crescimento do ensino secundário no Brasil. Em todo o país, colégios e ginásios públicos, mas principalmente privados, foram inaugurados. A criação do Ministério da Educação e Saúde Pública (MESP), a Reforma Francisco Campos, implementada por meio do Decreto $\mathrm{n}$ 웅. 18.890 , de 18 de abril de 1931 (BRASIL, 1942a), sendo consolidada pelo Decreto no 21.2141, de 4 de abril de 1932 (BRASIL, 1932), e o Decreto-lei no 4.244 (BRASIL, 1942b), de 9 de abril de 1942 - a Lei Orgânica de 1942 - impulsionaram esse processo, à medida que contribuíram para a construção de uma estrutura institucional, "não somente adequada à função de preparação básica ao ensino superior, como também orientada para uma finalidade mais compreensiva do adolescente para uma sociedade que ia começar a fazer-se mais complexa e dinâmica" (SILVA, 1969, p. 280). Esse dinamismo estava diretamente associado ao processo de industrialização brasileira, por substituição de importações, em uma lógica apoiada no estímulo ao crescimento do mercado interno. A partir de 1940, essa nova lógica da economia nacional gerou uma inversão do local de moradia dos 
brasileiros, que trocaram o campo pela cidade em busca de melhores postos de trabalho, que por sua vez demandavam maior qualificação.

Silva (1969, p. 314) destaca que "as análises do processo de expansão do ensino secundário nacional devem considerar as diversidades regionais que se ligam aos desequilíbrios do desenvolvimento econômico e social do país". Sendo o tema deste artigo o desenvolvimento dos cursos secundaristas no Distrito Federal entre os anos 1940 e 1960, será utilizado o conceito de "capitalidade". Segundo Freitag (2009) e Motta (2004), é possível caracterizar a "capitalidade" de uma cidade quando esta reúne condições para infundir um determinado espaço que se insere em um Estado. Neste sentido, a urbe é capaz de estabelecer hierarquias no interior do território que esta polariza: um centro que está hierarquicamente ligado a uma periferia. Por outro lado, a capital apresenta determinadas características, a saber, a liderança de determinados processos, a concentração da administração pública e de sua burocracia, a atração de correntes migratórias e a presença da intelectualidade. Tais esferas distintas colaboram para "alimentar dimensões do capital simbólico da cidade" (NUNES; MOURA, 2013, p. 98).

A cidade do Rio de Janeiro exerceu o papel de capital do Brasil por quase dois séculos. Desde a transferência da capital da colônia portuguesa do vice-reinado de Salvador para o Rio de Janeiro em 1793, a cidade foi palco das articulações políticas mais importantes, tendo em 1808 se tornado Corte e Capital da monarquia e do império português, mantendo sua posição após a independência e a proclamação da República. A "capitalidade" exercida durante muitos anos fez da cidade um espaço ímpar no país pela consequência da forte intervenção do Estado, que realizou reformas urbanísticas com o objetivo de torná-la uma referência de modernidade. Sendo assim, houve o aterramento de mangues e faixas litorâneas, a derrubada de morros, a abertura de túneis e a construção de pontes. Sevcenko (1998, p. 522) elenca outros fatores que intensificaram a visibilidade do

\section{Distrito Federal no território brasileiro:}

[...] o desenvolvimento dos meios de comunicação, o aprimoramento dos meios de transporte, a ampliação da imprensa ilustrada, a indústria fonográfica, o rádio e o cinema intensificaram esse papel da capital da República, tornando-a eixo de irradiação e caixa de ressonância das grandes transformações em marcha pelo mundo.

A criação do MESP dimensiona a concentração da burocracia educacional na cidade carioca. No Distrito Federal estavam concentradas as sedes de todos os órgãos do Ministério. Os serviços de inspeção administrativa e pedagógica estabelecidos pela Reforma Francisco Campos só existiam integralmente na capital:

A lei, infelizmente só pode ser posta em execução na capital, uma vez que as inspetorias Regionaes só podem ser organizadas, em virtude da lei que as estabeleceu, por pessoal habilitado em concurso. Ora, reduzidíssimo o número de inspetores de concurso... Portanto, foi impossível organizar outras Inspetorias Regionaes, além das duas que estão em funcionamento. Justamente por isso persiste ainda nos estados a inspeção puramente administrativa. Todavia é patente que só a fiscalização especializada dará resultados satisfatórios. 0 que na verdade interessa à nacionalidade é que se ministrem conhecimentos, que se instrua a mocidade e isso só poderá ser averiguado por inspetores nas diversas disciplinas do ensino secundário. (A SITUAÇÃO..., 1935, p. 4).

A construção da sede do MESP é outro referencial da "capitalidade" da cidade. Após a Revolução de 1930, o Estado comandado por Getúlio Vargas desejava divulgar a imagem de um Brasil novo. Neste sentido, os edifícios que abrigariam a estrutura da máquina burocrática deveriam ter tamanho e qualidade material que transmitisse a ideia de um Estado competente e inovador. Para a construção do prédio que abrigaria o novo ministério na Esplanada do Castelo foi convocado um concurso de anteprojetos arquitetônicos que, por um lado,

[...] atingiam setorialmente a sociedade, mobilizando-a em torno de torno de questões que o ministro considerava relevante, por outro, davam uma feição democrática a relação entre 
o Estado - promotor do concurso - e aqueles que se sujeitavam a um julgamento fundado em critérios técnicos, e não políticos. (LISSOVSKY; SÁ, 2000, p. 51).

0 propósito era afirmar por meio da arquitetura do prédio o projeto político do Estado: "assentar as bases da nacionalidade, edificar a pátria, forjar a brasilidade" (LISSOVSKY; SÁ, 2000, p. 62).
A concentração de recursos e funções na cidade do Rio de Janeiro, através da ampliação do movimento de comercialização e da expansão portuária, associadas à importância conquistada pelo setor financeiro e pela produção imobiliária, atraiu correntes migratórias principalmente das regiões Norte e Nordeste, acelerando o ritmo de crescimento da população.

Quadro 1 - Crescimento da população do Distrito Federal

\begin{tabular}{|c|c|c|c|}
\hline Ano & 1942 & 1951 & 1960 \\
\hline População & 1.764 .141 & 2.377 .000 & 3.307 .000 \\
\hline
\end{tabular}

Fonte: Distrito Federal (1956, p. 27).

A demanda por trabalhadores qualificados estimulou a criação de ginásios e colégios: em 1936, o número de estabelecimentos que ministravam ensino secundário no Distrito Federal era de 74 (DISTRITO FEDERAL, 1956); já em 1942, foram contabilizadas 381 instituições (INSTITUTO BRASILEIRO GEOGRAFIA E ESTATÍSTICA, 2020). Segundo Lourenço Filho (1950), a matrícula por habitante na capital da República era de 224 alunos por 10.000 habitantes; no estado de São Paulo essa proporção era de 96; e no Paraná, de 72. Essa expansão não assegurou aos cidadãos cariocas o acesso ao ensino público: até o final dos anos de 1940, estava restrito ao Colégio Pedro II, de âmbito federal.

A capital também concentrava intelectuais responsáveis pela elaboração e circulação de modelos pedagógicos, muitos catedráticos do Colégio Pedro II. Esta instituição, criada em 1837, retrata o papel pioneiro da capital no campo educacional, pois se trata da primeira instituição pública ${ }^{1}$ de ensino secundário brasileira, padrão para demais instituições e mantida até os dias atuais pelo Governo Federal. O Colégio Pedro II foi criado num contexto histórico em que a unidade de ensino era importante para a Nação, no sentido de mantê-la coesa e contribuir para a construção da sua

1 Nesse contexto, o sentido do termo "público" é compreendido com "estatal". identidade nacional, projeto instituído no período Imperial brasileiro, no qual não apenas o Colégio, mas o Instituto Histórico e Geográfico Brasileiro (IHGB) tinham protagonismo. $\mathrm{Na}$ 1a República, um dos fatos mais importantes ocorridos com relação ao ensino secundário é o estabelecimento da "equiparação", idealizada como um meio de uniformizar o ensino secundário no país a partir de um padrão de qualidade. Concedida aos colégios que seguissem o plano de ensino do Colégio Pedro II, a equiparação implica a concessão de um privilégio: a habilitação aos cursos superiores mediante aprovação nos exames realizados nos próprios colégios, sem a necessidade, portanto, de prestar exames no Colégio-modelo.

A partir dos aspectos apresentados que caracterizaram a "capitalidade" do município do Rio de Janeiro entre 1940 e 1960, as análises sobre a expansão do ensino secundário aqui propostas irão privilegiar as relações centro -periferia. Neste sentido, o processo de metropolização do Distrito Federal desenvolvido entre 1940 e 1950 será uma referência para este estudo, com o objetivo de compreender como a nova organização do espaço do Distrito Federal influenciou a distribuição das oportunidades educacionais aos seus moradores. 0 artigo está dividido em três partes. A primeira seção trata sobre o processo de metropolização do Distrito Federal e os impactos na distri- 
buição de ofertas culturais e oportunidades educacionais na cidade. A seguir será analisada a primeira fase da expansão do ensino secundário nos anos 1940. Ao final, relacionaremos os movimentos reivindicatórios dos estudantes e dos moradores na década de 1950 ao aumento do número de ginásios e colégios em todos os bairros da cidade.

\section{Metropolização e expansão do ensino secundário no Distrito Federal}

A Reforma Capanema, também conhecida como Lei Orgânica do Ensino Secundário Decreto-lei ${ }^{\circ} 4.244$, de 9 de abril de 1942 (BRASIL, 1942b) -, estabeleceu novas bases de organização do ensino secundário, que passou a ter como finalidades formar, em prosseguimento da educação oferecida no ensino primário, a personalidade integral dos adolescentes; acentuar e elevar, na formação espiritual dos adolescentes, a consciência patriótica e a consciência humanística; dar preparação intelectual geral que pudesse servir de base a estudos mais elevados de formação especial.

O ensino secundário passou a ser ministrado em dois ciclos. 0 primeiro compreendia um só curso: o curso ginasial. 0 segundo compreendia dois cursos paralelos: o curso clássico e o curso científico. Essa organização estrutural para o ensino secundário (BRASIL, 1942b) perdurou por quase trinta anos.

O curso ginasial, que tinha a duração de quatro anos, destinava-se a dar aos adolescentes os conteúdos considerados fundamentais do ensino secundário. 0 curso clássico e o curso científico, cada qual com a duração de três anos, tinham por objetivo consolidar a educação ministrada no curso ginasial, nesse sentido, desenvolvê-la e aprofundá-la. No curso clássico concorria para a formação intelectual, além de um maior conhecimento de filosofia, um acentuado estudo das letras antigas; no curso científico, essa formação era marcada por um estudo maior de ciências. A conclusão, seja do clássico, seja do científico, possibilitava o acesso, mediante vestibular, a qualquer curso superior.

Com relação aos tipos de estabelecimentos de ensino secundário, havia, conforme estabelecido pela Reforma Capanema (BRASIL, 1942b), dois tipos de estabelecimentos, o Ginásio e o Colégio. Ginásio era o estabelecimento de ensino secundário destinado a ministrar o curso de primeiro ciclo. Colégio era o estabelecimento de ensino secundário destinado a dar, além do curso próprio de ginásio, os dois cursos de segundo ciclo. 0 Colégio não podia eximir-se de ministrar qualquer dos cursos mencionados. Os estabelecimentos de ensino secundário não podiam adotar outra denominação que não a de Ginásio ou de Colégio. Trata-se de denominações vedadas a estabelecimentos de ensino que não se destinassem a oferecer o ensino secundário. Não era permitido que funcionasse no país estabelecimento de ensino secundário que fosse regido por legislação estrangeira.

Até 1945, não havia ginásios e colégios públicos municipais no Distrito Federal. Com exceção do Colégio Pedro II e do Colégio Militar, de âmbito federal, e do ginásio do Instituto de Educação, de administração municipal, as demais instituições eram todas privadas. É importante lembrar que em 1934 a capital adotou o modelo de Escola Técnica Secundária, que não era considerado como escolaridade em nível secundário pelo Decreto-lei no 4.244 (BRASIL, 1942b). Até o final dos anos 1930, existiam 11 Escolas Técnicas de Ensino Secundário distribuídas da seguinte forma: duas no Centro, uma na zona sul, duas na zona norte e seis na zona suburbana. Em 1941, Pio Borges, Secretário de Educação e Cultura do Distrito Federal, promoveu uma reforma no ensino municipal. Os cursos secundários foram suprimidos e as Escolas Técnicas Secundárias passaram a ministrar exclusivamente cursos profissionais. A reforma foi justificada pela necessidade do Distrito Federal em formar trabalhadores qualificados para a indústria: 
Já não é mais possível recrutar operários para a grande indústria na massa deseducada e desinstruída. Para as carreiras liberais bastam e sobram os institutos federais e o ensino particular. 0 governo não tem o dever - que dizemos nós - não tem o direito de fabricar doutores. (INICIA-SE..., 1940, p. 13).

0 relato de Pio Borges deixou claro que em sua administração os investimentos educacionais do Distrito Federal seriam nos ensinos primário e profissionalizante. A oferta de ensino secundário dependeria quase que exclusivamente do capital privado, uma vez que as instituições públicas permaneciam restritas ao Colégio Pedro II e às escolas militares. Neste contexto, a análise do processo de metropolização empreendido nesse período é importante, na medida em que, para Bourdieu (1997), o capital financeiro estabelece relações com espaço físico, determinando condições de apropriação dos demais tipos de capital (social e cultural). Assim, o grupo ou classe com posses de capital econômico pode passar a ocupar um lugar privilegiado no espaço social, portar uma distinção social. A proposta é refletir de que forma o processo de expansão do ensino secundário no Distrito Federal contribuiu para reforçar a instituição de espaços de distinção social.

\section{A metropolização do Distrito Federal}

Na década de 1940, o Distrito Federal era dividido administrativamente em 16 distritos que agregavam de três a quatro bairros. Neste período se intensificou o processo de metropolização que acentuou os contrates entre as regiões central e metropolitana. A metropolização intensifica a dispersão, amplificando a distância entre o Centro e os bairros, tendo como consequência os processos de fragmentação urbana, segregação socioespacial e periferização das populações.

Durante o Estado Novo, o interventor do Distrito Federal e catedrático de Física do Co- légio Pedro II, Henrique Dodsworth, realizou grande reforma urbana. Houve a abertura das Avenidas Presidente Vargas e Brasil, a duplicação do Túnel do Leme, a conclusão do Corte do Cantagalo, o alargamento da Avenida Tijuca, o término da demolição do Morro do Catete e o aterramento do Calabouço. Para Torres (2018), Getúlio Vargas, ao remodelar a cidade, pretendia transmitir para a nação a ideia de uma capital moderna e, ao mesmo tempo, incentivar a expansão do capitalismo industrial no Rio de Janeiro.

Ao longo da década de 1940, a especulação imobiliária no Distrito Federal pode ser verificada pelo número de licenças para a construção de prédios. As licenças concedidas para prédios com mais de três andares se concentraram em Copacabana, que se constituiu um bairro de classe média alta. Por outro lado, Oliveira e Lobo (1992) destacam que os problemas com habitação se agravaram durante a Segunda Guerra Mundial devido à expansão do operariado e à elevação do custo de construção. 0 rápido crescimento da população proletária vinda do Nordeste criou um déficit habitacional.

A ocupação dos subúrbios da cidade começa a se intensificar e a se consolidar, com base em iniciativas do Estado, do capital privado e do setor imobiliário. A expansão da E.F. Leopoldina Railway e inauguração da Avenida Brasil incentivaram a organização de pequenos núcleos habitacionais nos bairros mais distantes do Centro. Os Institutos Federais de Aposentadorias e Pensões firmaram acordo com a Prefeitura do Distrito Federal para a construção de conjuntos residenciais para moradores de favelas localizadas na zona sul. Entre os critérios para a escolha dos terrenos para as edificações estavam: facilidade e economia de transporte de preferência ferroviário, boas condições de salubridade e boa conformação topográfica, a proximidade dos centros industriais ou fácil acesso aos mesmos e o baixo custo unitário do terreno. Neste período, "apenas três dos 48 conjuntos residenciais construídos se situaram em áreas centrais, a grande maioria foi locali- 
zada em regiões afastadas." (OLIVEIRA; LOBO, 1992, p. 161)

Miyasaka (2016, p. 146), ao analisar esse processo, constata que parte dos subúrbios “deixou de ser essencialmente agrária, para abrigar contingente considerável de trabalhadores da indústria". Esse movimento populacional pode ser nitidamente percebido em alguns distritos, a saber, Vila Isabel, Méier, Penha, Madureira e Realengo.

Quadro 2 - Densidade da população por distrito

\begin{tabular}{|c|c|c|}
\hline \multicolumn{3}{|c|}{ Densidade de população do Distrito Federal } \\
\hline Distrito & $\mathbf{1 9 4 0}$ & $\mathbf{1 9 5 0}$ \\
\hline Centro & 11.544 & 8.907 \\
\hline Estácio & 15.970 & 16.733 \\
\hline Laranjeiras & 13.229 & 15.360 \\
\hline Botafogo & 2.911 & 3.876 \\
\hline Copacabana & 9.953 & 17.379 \\
\hline São Cristovão & 6.802 & 7.426 \\
\hline Tijuca & 1.805 & 2.239 \\
\hline Vila Isabel & 12.901 & 17.702 \\
\hline Méier & 5.746 & 7.105 \\
\hline Madureira & 3.717 & 5.750 \\
\hline Penha & 363 & 2.425 \\
\hline Jacarepaguá & 267 & 405 \\
\hline Realengo & 864 & 1.513 \\
\hline Campo Grande & 716 & 352 \\
\hline Santa Cruz & 106 & 155 \\
\hline Ilhas & 811 & 1.065 \\
\hline
\end{tabular}

Fonte: Distrito Federal (1956, p. 36).

Nos subúrbios, os terrenos mais próximos à estação do trem eram mais valorizados, criando uma hierarquia entre os imóveis. Pode-se dizer, então, "que a expansão das cidades, e no Rio de Janeiro não foi diferente, se deu orientada pela implantação das infraestruturas, especialmente por aquela de transporte público" (MAGALHÃES; IZAGA; PINTO, 2012, p. 23). Os trabalhadores com baixa renda viam nos lotes de terreno baratos em bairros industriais boas oportunidades de moradia. Nos jornais era comum o anúncio de projetos imobiliários para os mais pobres:

Visando cooperar para a solução do problema de moradia para maior número de habitantes das nossas grandes capitais, posso afirmar que Prolar foi a pioneira de um expressivo slogan concitando o povo a adquirir sua casa própria.

Estamos como um plano de loteamento de uma grande área no subúrbio de Irajá, para o que contamos esperar a boa vontade da Prefeitu- ra, principalmente com seu Departamento de Urbanismo, esperando que nos sejam dadas as facilidades indispensáveis à realização de um plano que ainda não foi até agora tentado no Brasil. Pretendemos concorrer com o nosso esforço para o embelezamento daquele aprazível subúrbio carioca, construindo cerca de 1600 modernos e confortáveis apartamentos, caso aprovado nosso projeto, para vende-los a preços módicos. (MAIS FÁCIL..., 1953, p. 5).

Nos anos 1920, a literatura já registrava o imaginário social que a precariedade urbana da cidade estaria presente apenas no subúrbio, em oposição às zonas sul e central da cidade. Lima Barreto (2012, p. 185) define os distritos suburbanos cariocas como "o refúgio dos infelizes. Os que perderam o emprego, as fortunas, os que faliram nos negócios, enfim, todos os que perderam a sua situação normal vão se aninhar lá". Esse autor lembra que nesses bairros "constituídos por um intricado labirinto de ruas e bibocas é que vive a maior parte da 
população, a cuja existência o governo fecha os olhos, embora lhe cobre atrozes impostos, empregados em obras inúteis e suntuárias noutros pontos do Rio de Janeiro" (BARRETO, 2012, p. 185).

As crônicas sobre a cidade demonstram que os problemas não se restringiam à zona suburbana. A constante falta d'água e a panes elétricas foram retratadas na marcha carnavalesca intitulada Vagalume, composta por Vítor Simon e Fernando Martins, em 1954. Ainda assim, é possível dizer que bairros de classe média alta localizados na zona sul eram mais urbanisticamente organizados e providos de equipamentos e serviços urbanos. 0 transporte público contava com linhas mais regulares de bonde e ônibus, que possibilitavam o acesso de seus moradores à região central.

A oferta de recursos culturais se concentrava no Centro, como o Teatro Municipal, o Teatro João Caetano, o Teatro Carlos Gomes, a Biblioteca Nacional e o Cinema Odeon. As regiões conhecidas como suburbanas, por margearem a linha férrea, apresentavam um distanciamento social. Para Bourdieu (1997), os lugares no espaço social são definidos pelas posições geradas pela distribuição desigual do volume e da composição do capital (econômico, social e simbólico), as quais expressam as relações de dominação na sociedade entre as classes sociais.

As regiões suburbanas se constituíam espaços segregados, pois eram afastadas geograficamente do Centro. Seus moradores trocavam o sonho da casa própria pela exclusão dos serviços urbanos. Nos anúncios dos terrenos e casas eram valorizadas as linhas de ônibus existentes, a proximidade da estação de trem, a água encanada, as instalações de luz elétrica, mas não eram citadas a presença de escolas ou outras instituições culturais. Tinham pouca mobilidade urbana, pois os bairros dispunham de transporte precário, principalmente nos finais de semana, quando não havia expediente de trabalho. Ainda que houvesse distritos suburbanos que concentravam muitos cinemas como Méier e Madureira, não havia diversidade de ofertas culturais como teatros, museus e bibliotecas.

Quadro 3 - Recursos culturais por distrito - 1955

\begin{tabular}{|c|c|c|c|}
\hline \multicolumn{4}{|c|}{ Recursos culturais no Distrito Federal } \\
\hline Distrito & Cinema & Teatro & $\begin{array}{c}\text { Volumes disponíveis em } \\
\text { biblioteca }\end{array}$ \\
\hline Centro & 19 & 9 & 1.136 .126 \\
\hline Estácio & 2 & 0 & 4.034 \\
\hline Laranjeiras & 3 & 1 & 184.963 \\
\hline Botafogo & 6 & 0 & 166.524 \\
\hline Copacabana & 14 & 4 & 12.660 \\
\hline São Cristóvão & 3 & 0 & 8.650 \\
\hline Tijuca & 5 & 0 & 54.152 \\
\hline Vila Isabel & 4 & 0 & 47.763 \\
\hline Méier & 22 & 0 & 32.126 \\
\hline Madureira & 27 & 1 & 3.385 \\
\hline Penha & 9 & 0 & 150.000 \\
\hline Jacarepaguá & 3 & 0 & 14.604 \\
\hline Realengo & 2 & 0 & 0 \\
\hline Campo Grande & 5 & 0 & 4.590 \\
\hline Santa Cruz & 4 & 0 & 4.540 \\
\hline
\end{tabular}

Fonte: Distrito Federal (1956, p. 220). 
Outro aspecto importante para a compreensão da realidade do Distrito Federal era a presença de favelas em bairros nobres da cidade. Assim, o índice da população escolarizada e alfabetizada na faixa etária dos 5 aos 14 anos não apresentavam grande disparidade, à medida que a população favelada era tão ou mais desprovida de condições que moradores de bairros da zona norte e do subúrbio.

A população de escolarizados alfabetizados é maior nos distritos da zona sul e do centro, mas há distritos suburbanos como Méier e Penha com índices melhores que o distrito de Botafogo localizado na zona sul. Os piores índices são os dos distritos mais distantes da área central, a saber Campo Grande e Santa Cruz.

Quadro 4 - População de 5 a 14 anos alfabetizada por distrito em 1950

\begin{tabular}{|c|c|c|c|}
\hline \multicolumn{4}{|c|}{ População de 5 a 14 anos alfabetizada no Distrito Federal em 1950 } \\
\hline Distrito & População total & População alfabetizada & Percentual \\
\hline Centro & 9.405 & 6.613 & $69,97 \%$ \\
\hline Estácio & 21.724 & 16.733 & $77,02 \%$ \\
\hline Laranjeiras & 21.079 & 14.884 & $70,61 \%$ \\
\hline Botafogo & 22.987 & 14.642 & $63,69 \%$ \\
\hline Copacabana & 15.470 & 10.784 & $69,70 \%$ \\
\hline São Cristovão & 12.831 & 8.546 & $66,60 \%$ \\
\hline Tijuca & 12.723 & 8.170 & $64,21 \%$ \\
\hline Vila Isabel & 39.073 & 25.980 & $66,49 \%$ \\
\hline Méier & 51.671 & 35.616 & $68,92 \%$ \\
\hline Madureira & 76.855 & 44.878 & $58,39 \%$ \\
\hline Penha & 27.263 & 17.527 & $64,28 \%$ \\
\hline Jacarepaguá & 21.645 & 12.331 & $56,96 \%$ \\
\hline Realengo & 48.068 & 25.836 & $53,74 \%$ \\
\hline Campo Grande & 19.058 & 8.885 & $46,62 \%$ \\
\hline Santa Cruz & 7.749 & 3.343 & $43,14 \%$ \\
\hline Ilhas & 7.558 & 4.271 & $56,50 \%$ \\
\hline
\end{tabular}

Fonte: Distrito Federal (1956, p. 174).

Os dados também revelam que, em geral, a população escolar, mesmo a dos subúrbios, apresenta resultados bem melhores que a média nacional.

\section{Os anos 1940: a primeira fase da expansão}

O quadro abaixo demonstra a distribuição de colégios e ginásios pelos distritos do Distrito Federal. Os distritos da zona sul eram Laranjeiras, Botafogo e Copacabana. A zona norte era composta pelos distritos da Tijuca e do Estácio. Os demais eram categorizados como suburbanos.

Na região central, considerada como "marco zero" da cidade, estava localizado o Colégio Pedro II, instituição criada em 1837, mantida pelo governo federal, era considerada modelar para o ensino secundário nacional. 0 colégio conferia prestígio aos seus alunos e professores. Sua Congregação, formada por 21 professores, intelectuais como Fernando Antonio Raja Gabaglia (catedrático de Geografia e Decano da Congregação), Honório de Souza Silvestre (catedrático de Geografia) e Euclides de Medeiros Guimarães Roxo (catedrático de Matemática), possuía uma grande produção intelectual, 
além de ser responsável pela elaboração dos programas e ocupar cargos importantes em
Ministérios, Secretarias e comissões, como a

Comissão Nacional do Livro Didático.

Quadro 5 - Colégios e Ginásios por distrito

\begin{tabular}{|c|c|c|c|c|c|c|c|c|c|c|}
\hline \multicolumn{11}{|c|}{ Colégios e Ginásios do Distrito Federal } \\
\hline \multirow[t]{3}{*}{ Distrito } & \multicolumn{5}{|c|}{1945} & \multicolumn{5}{|c|}{1955} \\
\hline & \multicolumn{2}{|c|}{ Particular } & \multicolumn{2}{|c|}{ Público } & \multirow[t]{2}{*}{ Total } & \multicolumn{2}{|c|}{ Particular } & \multicolumn{2}{|c|}{ Público } & \multirow[t]{2}{*}{ Total } \\
\hline & $\mathbf{C}$ & G & C & G & & $\mathbf{C}$ & $\mathbf{G}$ & $\mathbf{C}$ & G & \\
\hline Centro & 3 & 3 & 1 & 0 & 7 & 8 & 7 & 1 & 1 & 17 \\
\hline Estácio & 2 & 0 & 0 & 0 & 2 & 6 & 3 & 2 & 1 & 12 \\
\hline Laranjeiras & 4 & 3 & 0 & 0 & 7 & 7 & 3 & 4 & 0 & 14 \\
\hline Botafogo & 8 & 3 & 0 & 0 & 11 & 13 & 5 & 0 & 0 & 18 \\
\hline Copacabana & 4 & 5 & 0 & 0 & 9 & 9 & 7 & 0 & 0 & 16 \\
\hline São Cristóvão & 1 & 3 & 0 & 0 & 4 & 3 & 2 & 0 & 0 & 5 \\
\hline Tijuca & 14 & 15 & 0 & 1 & 29 & 12 & 14 & 0 & 2 & 28 \\
\hline Vila Isabel & 0 & 0 & 0 & 0 & $\mathbf{0}$ & 3 & 5 & 0 & 1 & 9 \\
\hline Méier & 3 & 9 & 0 & 0 & 12 & 6 & 11 & 0 & 5 & 22 \\
\hline Madureira & 2 & 1 & 0 & 0 & 3 & 2 & 4 & 0 & 2 & 8 \\
\hline Penha & 2 & 1 & 0 & 0 & 3 & 5 & 11 & 0 & 0 & 16 \\
\hline Jacarepaguá & 1 & 1 & 0 & 0 & 2 & 0 & 1 & 0 & 0 & 1 \\
\hline Realengo & 0 & 0 & 0 & 0 & $\mathbf{0}$ & 0 & 4 & 1 & 2 & 7 \\
\hline Campo Grande & 1 & 0 & 0 & 0 & 1 & 1 & 4 & 0 & 1 & 6 \\
\hline Santa Cruz & 0 & 0 & 0 & 0 & $\mathbf{0}$ & 0 & 0 & 1 & 1 & 2 \\
\hline Ilhas & 0 & 0 & 0 & 0 & 0 & 1 & 0 & 0 & 1 & 2 \\
\hline Total & 45 & 44 & 1 & 1 & 91 & 76 & 81 & 9 & 17 & 183 \\
\hline
\end{tabular}

Fonte: Elaborado pelos autores deste artigo a partir de Revista Brasileira de Estudos Pedagógicos (1945, p. 290).

Para Massunaga (1989), do ponto de vista legal, no texto da Lei Orgânica do Ensino Secundário promulgada em 1942, o Colégio não era mais considerado padrão, embora isso não signifique o abandono do objetivo de uniformizar o ensino secundário, um dos principais objetivos do Ministro Gustavo Capanema. Não haveria lugar para o padronato do Colégio, num contexto em que se desejava implementar uma nova ordem política e social através do regime autoritário, centralizador de poderes e de decisões. Massunaga (1989, p. 147), ao entrevistar um professor que vivenciou este período, revela que "Capanema mostrava certa má vontade com relação ao Colégio". Entretanto, essa situação parece ocorrer nos bastidores, uma vez que "no plano das relações formais e no trato público, durante o tempo em que se mantém a frente do Ministério, Capanema conserva relações respeitosas, de formal cordialidade e comparece ao Colégio em diversas ocasiões" (MASSUNAGA, 1989, p. 147).

Como a única instituição pública de Ensino Secundário era o Colégio Pedro II, a expansão do ensino secundário na década de 1940 dependeu exclusivamente do capital privado. A lógica da dinâmica imobiliária impactou a distribuição de colégios e ginásios na cidade do Rio de Janeiro. A renda era o fator mais importante para atrair instituições particulares de ensino para os distritos. Como a Prefeitura do Distrito Federal não tinha uma política educacional de expansão do ensino secundário, os bairros com maior densidade populacional eram desassistidos deste nível de ensino. Os setores especulativos disponibilizaram aos moradores de bairros mais valorizados, com poder aquisitivo, a oportunidade de escolarização secundária, colaborando para o aumento da fragmentação social.

Copacabana era um bairro consolidado em que moravam as classes alta e média, com 
boas fontes de emprego e serviços, como os funcionários públicos com melhores cargos e salários. Apenas os moradores deste distrito que tinham renda para pagar as mensalidades contavam várias possibilidades de acesso ao ensino secundário: instituições laicas, colégios religiosos tradicionais, ginásios e colégios que ofereciam os cursos clássico e científico. É importante destacar que a população residente em favelas desses distritos também era excluída dos cursos secundários. Nas páginas dos jornais destinadas aos anúncios imobiliários é possível encontrar ofertas de prédios luxuosos para a fundação de novos colégios pela iniciativa privada:

\section{COPACABANA}

Leilão luxuoso e grande prédio para residência próprio para embaixada ou colégio. Rua Raul Pompéia, 94.

O leiloeiro Paula Afonso venderá em leilão amanhã, 27 de maio de 1946, às 16 horas em frente ao mesmo, esplêndido prédio de excepcional construção, com interior decorado a ouro e vários trabalhos artísticos em relevo, esmerado acabamento, lindos lustres e lanternas francesas em bronze e cristal de bacarat. Salões ricamente decorados. Anúncio detalhado no Jornal do Comércio de domingo. (COPACABANA, 1946, p. 18).

Os donos de colégios também publicavam anúncios procurando terrenos para fundação de novas unidades de ensino:

Prédio para colégio

Conceituado colégio em Copacabana precisa comprar ou alugar nesse bairro ou em Ipanema grande prédio (ou dois prédios contíguos) para instalação de novo departamento. É indispensável uma área livre de pelo menos 400 metros quadrados e facilidade de condução. Gratifica-se que der informações aproveitáveis - Telefone 27-4797. (PRÉDIO PARA..., 1942, p. 12).

A abertura do Túnel do Leme aproximou os moradores do Distrito de Copacabana ao Distrito de Botafogo, que passou a ser conhecido como "bairro dos estudantes", pois havia o maior número de ginásios e colégios, o que ampliava as ofertas de escolarização secundá- ria. As propagandas das instituições de ensino secundário nos dão pistas do perfil dos seus alunos, pois destacavam o acesso aos cursos universitários. O Instituto Juruena, por exemplo, que era localizado à Praia de Botafogo, enfatizava em seus anúncios, publicados em periódicos de grande circulação, a sua seção complementar: "cursos para todas as escolas superiores do paiz: Medicina, Medicina Veterinária, Pharmácia, Odontologia, Engenharia, Agronomia, Architetura, Chímica, Direito e Philosophia" (INSTITUTO..., 1940, p. 6).

Mesmo na zona norte, a fundação dos ginásios e colégios nos bairros obedeceu a lógica da especulação imobiliária; assim, os distritos mais valorizados pela proximidade ao Centro, e com moradores com maior poder aquisitivo, dispunham de mais instituições de ensino secundário. A Tijuca, por exemplo, tinha "ares de bairro burguês". Possuía vários serviços privados, o maior cinema da América do Sul, o Olinda, clubes, hospitais e hotéis. Em anúncios de venda de apartamentos, a proximidade dos colégios e ginásios era destacada:

\section{APARTAMENTOS \\ Rua Mariz e Barros}

Vendo próximo ao Instituto de Educação, os dois últimos apartamentos de frente, com saleta 3 quartos, banheiro completo, cozinha, quarto e dependência de empregada, terraço com tanque e varanda.

Construção adiantada. Parte financiada (APARTAMENTOS, 1946, p. 18).

Edifício Gotin Maclair

Rua São Francisco Xavier, 116 e 118

Em bairro essencialmente familiar

Circundado pelos cinco estabelecimentos oficiais de Ensino Secundário do Distrito Federal: Colégio Militar, Instituto de Educação, Colégio Pedro II, Colégio Orsina da Fonseca e Escola Técnica Nacional. (EDIFÍCIO..., 1952, p. 10).

0 bairro da Tijuca era o que tinha mais instituições de ensino secundário do Distrito Federal: ginásios e colégios públicos e particulares. 0 poder aquisitivo de seus morado- 
res, assim como o sistema de transporte, que contava com bondes e ônibus, podem ser os motivos pelos quais vários mantenedores de colégios e ginásios se interessaram pelo bairro. Nos classificados também é possível encontrar anúncios de pessoas procurando prédios para fundar colégios:

\section{Prédio na Tijuca}

Precisa-se na Tijuca de prédio grande para a instalação de um colégio. Informações para o professor Veiga pelo telefone 38-6698. (PRÉDIO NA..., 1942, p. 13).

O Méier era um distrito do subúrbio que se diferenciava dos demais na zona suburbana. Segundo Schwarcz (2017), o Méier era o subúrbio mais próximo à região central, com muitos moradores que eram servidores do Estado. Esse perfil socioeconômico dos habitantes garantiu uma estrutura urbana melhor: contavam com uma variedade de comércio, cinemas e teatro. Por estas condições, o Méier ganhou o título de "capital do subúrbio". Se destacava em relação às instituições educacionais, possuindo o mesmo número de ginásios e colégios que outros distritos localizados na zona sul.

Enquanto todos os distritos centrais, da zona sul e da zona norte, possuíam vários colégios e ginásios, havia distritos na zona suburbana que não contavam sequer com uma instituição de ensino secundário, como Realengo e Santa Cruz:

Pasme o leitor com isso! Em Santa Cruz não existe uma escola secundária!

Para cursar a escola de humanidades a juventude local tem que vencer a distância de 60 quilômetros percorridos, aliás de modo mais enfadonho por estradas cheias de sulcos e que evidenciam o imperdoável descaso das autoridades municipais por uma localidade em pleno Zenith de um desenvolvimento agrícola que honra a população do denominado sertão carioca. (SEM ESCOLA..., 1941, p. 2).

Outros distritos como Jacarepaguá e Campo Grande dispunham de apenas uma instituição de ensino secundário.

Nesse sentido, é importante perceber que Vila Isabel, sendo distrito operário e muito povoado por concentrar muitas fábricas, não ofertava aos seus moradores nenhuma opção de colégio ou ginásio. Essa escassez de colégios e ginásios em bairros com grande densidade populacional demonstra que os mantenedores de colégios não tinham interesse pelos distritos populosos, mas pobres e afastados do Centro, porque dificilmente obteriam lucro com suas atividades.

A ausência de instituições públicas municipais em todos os distritos representa a impossibilidade das camadas populares de acesso ao ensino secundário. Distantes do Centro e com transporte precário, ou moradores de favelas na zona sul, os estudantes não tinham alternativa caso não pudessem pagar as mensalidades dos poucos ginásios e colégios próximos a suas residências.

Nesse contexto, as Escolas Técnicas Secundárias da Prefeitura do Distrito Federal, até o final da década de 1930, tinham um papel muito importante, na medida em que se tornavam a única possibilidade disponibilizada pelo Estado para que os estudantes prosseguissem os estudos após o primário, mesmo que na modalidade técnico-profissional.

Luchmann (2011) destaca as diferentes estratégias presentes nos repertórios de ação dos movimentos sociais: piquetes, marchas, demonstrações, ocupações, bloqueios, abaixo-assinados, panfletagem, reuniões políticas, cartas, declarações na imprensa e lobbies. Os participantes destas ações contestadoras escolhem seus artifícios a partir das oportunidades do contexto. Quando Pio Borges propôs a extinção dos cursos secundários nas escolas técnicas, os alunos fizeram denúncias aos jornalistas para que sua luta pela manutenção dos ginásios ganhasse visibilidade e o apoio da população: "O Radical, atendendo ao que lhes pediram os referidos alunos da Escola Amaro Cavalcanti, pos-se desde logo em contato com alta personalidade do ensino municipal, que nos deu as seguintes explicações, que refletem com segurança a orientação do Coronel Pio Borges" (NÃO HÁ..., 1940, p. 2). 
Com o fim do Estado Novo, os jornais passaram a apresentar matérias sobre a reivindicação dos cariocas para que fossem criados ginásios públicos. Neste sentido, é possível notar a resistência da Secretaria de Ensino Técnico Profissional à abertura de ginásios que não tivessem curso profissionalizante. Em 1947, o Decreto Municipal no 8.976 (DISTRITO FRDERAL, 1947), de 16 de outubro de 1947, estabelece que nos ginásios nos quais houvesse oficinas, a frequência a estas era obrigatória a todos os alunos matriculados.

Em 1946, foram inaugurados dois ginásios municipais que não eram técnicos: o Ginásio Municipal Barão do Rio Branco, em Madureira, e o Ginásio Benjamin Constant, em Santa Cruz. A inauguração destes estabelecimentos indicava o início de uma mudança na orientação da política educacional do Distrito Federal e representou uma conquista dos moradores desses distritos suburbanos, que não contavam com instituições públicas de ensino secundário.

Os ginásios iniciaram suas atividades em condições precárias. Os jornais publicaram, ainda no primeiro ano de funcionamento do Ginásio Rio Branco, as denúncias de pais alunos que estavam indignados com a falta de professores:

Venho pedir-lhe a fineza de reclamar contra a grave situação em que se acha o Ginásio Barão do Rio Branco de Madureira, que inaugurado pelo Prefeito Filadelfo Azevedo, em fevereiro último até hoje não tem o corpo docente completo faltando muitos professores entre eles o de Francês, de Desenho e de outras matérias. Não houve nenhuma aula até hoje dessas matérias embora estejamos na época de provas parciais, o que motivou uma reclamação do Ministério da Educação para que completasse o corpo de docente até julho vindouro, sob pena de ser fechado o ginásio, onde os 400 alunos estão esperando o ensino gratuito anunciado pela Prefeitura. (CONTINUA..., 1946, p. 2).

Entre os fatores que prejudicaram o funcionamento dos ginásios municipais estava a falta de um prédio próprio, pois foram erguidos nas dependências de outras escolas, e a falta de mobilidade urbana, já que a ligação entre o Centro e os distritos suburbanos era feita apenas por trem, com horários restritos, o que dificultava o acesso dos professores às instituições:

Por ofício designado ao diretor da Estrada de Ferro Central do Brasil, o prefeito atendendo ao pedido da Secretaria Geral da Educação e Cultura, consultou aquela entidade sobre a possiblidade de ser acrescentado para transporte de professores com exercício na zona do ramal de Santa Cruz, mais um carro especial que parte da estação D. Pedro II às 6:15 com destino a Santa Cruz, exclusivamente destinado a condução e funcionários do Ministério da Aeronáutica e cujo horário tornaria possível as referidas professoras manter a regularidade e a frequência regulares nas escolas. (TREM..., 1947, p. 5).

Os relatos transmitem a sensação de que os estudantes estavam sempre ameaçados em relação ao funcionamento dos ginásios municipais. Ao mesmo tempo, nos dão indícios que o ensino secundário não era uma prioridade da Prefeitura do Distrito Federal. A cada início do ano letivo os problemas se acumulavam: a falta de professores, os prédios inacabados, a falta de mobiliário, os poucos materiais didáticos. Muitas vezes, as demandas só eram atendidas ao final do primeiro semestre, comprometendo a aprendizagem dos alunos.

O processo de reorganização do ensino no Distrito Federal iniciou com o fim do Estado Novo e se intensificou em 1948, com a assinatura de um decreto municipal que substituía o ensino industrial das escolas técnicas da Prefeitura pelo curso ginasial, mantendo-se a obrigatoriedade da frequência dos alunos às oficinas existentes nas referidas escolas. 0 Prefeito Ângelo Mendes de Morais assim justificou sua decisão:

[...] o ensino básico popular não deve terminar na escola primária e, que de acordo com a experiência pedagógica moderna não é aconselhável iniciar os cursos de especialização profissional logo após o primário, devendo-se assim substituir o referido ensino por outro que assegure aos adolescentes uma formação mais desenvolvida e que lhes proporcione na idade própria, o ensejo de escolher uma carreira adequada ás suas vocações. (REORGANIZAÇÃO..., 1947, p. 2). 


\section{Os anos 1950}

Nos anos 1950 ocorreu um aumento considerável do número de colégios e de ginásios em todos os distritos. Neste processo destacamos que o maior crescimento se deu proporcionalmente no número de instituições privadas. Outros aspectos importantes foram o aumento de unidades do Colégio Pedro II e a reorganização do ensino secundário do Distrito Federal, que criou ginásios e colégios municipais.

O final da década de 1940, no Distrito Federal, foi marcado pelo aumento do custo de vida: alimentação, transporte, habitação, vestuário, higiene, transporte e combustível. A classe operária tinha que se submeter a um intenso ritmo de trabalho para assegurar condições mínimas de sobrevivência. Entre os anos de 1951 e 1954 houve uma onda de greves, motivadas pela contenção salarial praticada pelo governo, pelos constantes cortes de energia, que obrigava a redução de turnos e diminuição de salários, a precariedade dos transportes e o aumento dos aluguéis. Também é possível verificar a insatisfação das camadas médias urbanas com a falta de oportunidades educacionais no Distrito Federal, em especial no ensino secundário.

O período de expansão do Colégio Pedro II se inicia nos anos 1950, com a criação, em 1952, das Unidades Norte e Sul, atuais Unidades Engenho Novo e Humaitá, respectivamente:

Cumprindo o programa que se traçou de promover a difusão do ensino no país de todos os níveis criando facilidades para os que desejam realmente aprender, o Ministro Simões Filho a frente de uma pasta que se vem caracterizando por uma atividade bem orientada em harmonia com as diretrizes do governo, tomou uma decisão das mais louváveis ao ordenar as providências para o desdobramento do Colégio Pedro II em duas novas seções: a da zona sul e a da zona norte possibilitando assim melhores oportunidades para estudantes saídos de dois dos mais densos núcleos de população dessa capital. (MAIS DE..., 1952, p. 2).

Todos os anos, o concurso de admissão reunia muitos candidatos. Vários vinham de dis- tritos distantes da região central para estudar no tradicional colégio. No entanto, a aprovação na rigorosa prova não era o único desafio a ser vencido pelos jovens estudantes:

Neste primeiro contato com as bancas examinadoras, os 1300 candidatos aos cursos do tradicional colégio viveram um instante decisivo para suas esperanças dada a sua condição eliminatória da matéria em pauta. Os exames iniciados ontem deveriam ter começo às 8 horas. Todavia devido as dificuldades de condução devido ao mau tempo e com o propósito de não prejudicar os que moram longe, o diretor do colégio professor Gildásio Amado determinou uma tolerância de duas horas. E foi mandando servir café com biscoitos, amenizando assim a longa espera dos que chegaram cedo. (CANDIDATOS..., 1951, p. 8).

No movimento de expansão do colégio, a carência de colégios e a dificuldade que os estudantes tinham para se locomover para a região central foram fatores importantes para a escolha dos bairros em que seriam instaladas as novas unidades:

A dependência do Colégio Pedro II, cuja criação foi sugerida para atender aos educandos que residem afastados do centro urbano ficará localizado entre Vila Isabel e Engenho Novo, nas proximidades do Jardim Zoológico. 0 prédio em questão ainda se encontra ocupado. (NO ENSINO, 1951, p. 4).

Em 1962, a instituição já contava com 863 professores das várias categorias, conforme o Anuário do Colégio Pedro II (COLÉGIO PEDRO II, 1963), referente ao período de 1951 a 1961, publicado em 1963.

Fechando o $1^{\circ}$ ciclo de expansão do Colégio, a Unidade Tijuca é criada em 1957 e teve como justificativa a demanda por matrículas de ingresso na $1^{a}$ série do Curso Secundário (atual $6^{\circ}$ ano do ensino fundamental), por meio do Histórico Exame de Admissão.

Por determinação do Presidente Kubitschek foi alugado o Colégio Felisberto Menezes para abrigar cerca de 600 alunos aprovados no concurso para a primeira série ginasial no Pedro II, e que por falta de vagas não seriam matriculados esse ano. 
O Colégio Felisberto Menezes funcionará inicialmente como uma extensão do Colégio Pedro II na Tijuca até ser adquirido pelo governo e transformado em anexo daquele tradicional estabelecimento de ensino.

O diretor do externato do Pedro II, sr. Clóvis Monteiro declarou que as aulas no Colégio Felisberto Menezes terão início provavelmente ainda essa semana no turno da tarde. Posteriormente todo o prédio ficará a disposição do Pedro II, quando então passarão a funcionar os demais turnos.

Pais de alunos agradecidos ao Presidente Juscelino Kubitschek pela sua providencial e patriótica decisão, hoje ás 11 horas, concentraram-se diante do Colégio Pedro II, para homenagear o presidente e propor que o novo anexo do Pedro II seja denominado Juscelino Kubitschek. (ACABOU..., 1957, p. 2).

Essas três seções (Norte, Sul, Anexo Tijuca) tiveram uma extraordinária procura, obrigando o Colégio Pedro II a estabelecer três turnos de aulas. É possível verificar o crescimento do número de matrículas a partir dos quadros a seguir.

Quadro 6 - Alunos Matriculados no Colégio Pedro II no Período de 1940 a 1945

\begin{tabular}{|c|c|}
\hline Ano & $\mathbf{N}^{\circ}$ de matrículas \\
\hline 1940 & 2.921 \\
\hline 1941 & 3.160 \\
\hline 1942 & 4.098 \\
\hline 1943 & 4.083 \\
\hline 1944 & 4.018 \\
\hline 1945 & 3.556 \\
\hline
\end{tabular}

Fontes: Fundação Getúlio Vargas (2019).

Quadro 7 - Alunos Matriculados no Colégio Pedro II no Período de 1955 a 1960

\begin{tabular}{|c|c|}
\hline Ano & $\mathbf{N}^{\circ}$ de matrículas \\
\hline 1955 & 3.856 \\
\hline 1956 & 5.205 \\
\hline 1957 & 5.847 \\
\hline 1958 & 6.690 \\
\hline 1959 & 7.863 \\
\hline 1960 & 10.269 \\
\hline
\end{tabular}

Fontes: Elaborado pelos autores deste artigo a partir de Colégio Pedro II (1963).
Cada uma das seções teve a sua administração orientada por professores do quadro de Catedráticos e, posteriormente, por outros membros do magistério escolar. Receberam, portanto, os professores da geração dos anos 1950, mas havia nitidamente ainda presente a geração anterior.

No início da década de 1950, os moradores de vários distritos do Distrito Federal reivindicavam a construção de ginásios e colégios próximos a suas casas. Os moradores de Marechal Hermes colheram assinaturas para reivindicar não só a construção do ginásio, mas a localização que melhor lhes atenderia:

Tendo Prefeito João Carlos Vital determinado providências para a construção de um ginásio municipal em Marechal Hermes, com capacidade para 12 classes, os moradores daquele subúrbio enviaram àquela autoridade um memorial com 2 mil assinaturas agradecendo a iniciativa e solicitando ao governador da cidade, o aproveitamento de prédio em construção a rua Juriaré, que melhor atenderá às necessidades dos moradores locais ao invés de localizar o ginásio a rua Capitão Rubens como foi autorizado por s.excia. (MARECHAL..., 1951, p. 8).

Os jornais cariocas que tinham um posicionamento político contrário ao prefeito disponibilizavam espaços privilegiados para publicação de matérias, que divulgavam as denúncias de moradores como a falta de água, de luz, de pavimentação das ruas e a demanda por vagas no ensino secundário. A notícia a seguir foi publicada na coluna Gerico, do Correio da Manhã. O jornalista Bueno Filho escrevia em sua coluna as irregularidades delatadas por moradores dos bairros, que escreviam cartas solicitando sua visita.

Novos problemas em Oswaldo Cruz.

Ruas pavimentadas mas sem iluminação.

0 ginásio inacabado vem fazendo muita falta aos moradores.

Não há em Osvaldo Cruz, daquele lado, escolas primárias. Os alunos vão longe. Mais de $20 \mathrm{mi}-$ nutos a pé, atravessando ruas de tráfego intenso sujeito a riscos de atropelamentos. Por outro lado nem sempre as mães podem levar seus filhos á escola, pois isso exige grande sacrifício 
em face dos seus afazeres domésticos. Se não existem escolas públicas, particulares é o que não faltam, particularmente na Avenida Ernani Cardoso. Lá os pais que não raro tem cinco filhos na idade escolar, deixam parte do pouco que ganham e que certamente irá fazer falta em casa. 0 bom número de estabelecimentos particulares nada mais é do que uma consequência da falta de escolas municipais.

As dificuldades para os pais aumentam com a idade dos filhos. No ginásio os preços cobrados são mais caros, e raros são os que podem manter mais de um filho nos ginásios particulares, notadamente no ano em curso com a elevação dos preços nesses estabelecimentos de ensino, o que vem acarretando grande número de reclamações.

Se o ginásio da rua Jaguaré tivesse sido concluído, de acordo com fora planejado, estaria agora em funcionamento. Abrigando algumas centenas de brasileirinhos que estão sacrificados, impossibilitados de estudar. (BUENO FILHO, 1952, p. 1).

0 relato sobre a dificuldade dos pais para pagar as mensalidades, motivo pelo qual muitos tinham que tirar seus filhos dos ginásios particulares, se repetiu em várias reportagens, dando indícios que esse fator tenha estimulado a organização de movimentos pela construção de ginásios públicos no Distrito Federal.

Sabe a Prefeitura e mais do que ninguém que que alunos saem das escolas públicas primárias e acabou-se salvo quando os seus pais podem arcar com as grandes despesas que se fazem necessárias à manutenção de um rapaz no ginásio. Quando a família tem um só filho isso ainda é possível. Mas quando são numerosos não qualquer esperança. No entanto a municipalidade tem conhecimento da existência de milhares de famílias pobres, as que residem em favelas próximas, as grandes favelas da cidade, aliás como a da Rocinha, a da Praia do Pinto, da Gávea e outras. (HÁ TRÊS..., 1956, p. 4).

Os jornais também passaram a publicar com regularidade as ações de outro elemento que reforçou a luta pelas instituições secundaristas: o movimento estudantil, liderado pela Associação Metropolitana dos Estudantes Secundários (AMES) e pela União Nacional dos Estudantes
(UNE). Em 1953, realizaram uma campanha pelo congelamento das mensalidades, que teve uma passeata que reuniu mais de dois mil jovens secundaristas:

Os estudantes secundários estão de parabéns pela magnífica demonstração de unidade realizada sexta-feira com a jornada de protesto. Mais uma vez a AMES demonstrou sua qualidade incontestável de vanguardeira das causas estudantis. Assim estudantes e suas entidades deverão agir para o futuro. Estou certo que todos nós jovens estudantes, trilhando o caminho da unidade e da confraternização iremos até a vitória. Na verdade neste momento tudo nos une para conseguirmos melhores oportunidades de estudo para a juventude de nosso país. (MANIFESTO..., 1953, p. 8).

Em 1954 houve a continuidade do processo de reorganização da rede de ensino pública do Distrito Federal. Ocorreu o investimento na criação de ginásios e mais escolas técnicas passaram a ministrar apenas o ensino secundário, tirando a nomenclatura Escola Técnica Secundária, passando a ser nomeadas como Ginásio Municipal:

Algumas escolas técnicas passaram ministrar
apenas o ensino secundário, tirano a nomen-
clatura Escola Técnica passando a ser assim
nomeadas: Ginásio Municipal João Alfredo,
Ginásio Visconde de Cairu e Ginásio Municipal
Bento Ribeiro. Outros Colégios permaneceram
ministrando apenas o Ensino Secundário: Giná-
sio Professor Daltro Santos, Ginásio Professor
Clóvis Monteiro e os Colégios Municipais Prefei-
to Mendes de Morais, Paulo de Frontin e Barão
do Rio Branco. (RESTABELECIDO..., 1954, p. 4).

Essa reorganização beneficiou principalmente os distritos suburbanos como Méier, Santa Cruz, Campo Grande, Jacarepaguá e Realengo, onde foram inaugurados ginásios municipais. Outra ação importante no processo de expansão do ensino secundário municipal foi a criação de ginásios noturnos, que visavam ao aproveitamento de prédios escolares, com instituição do terceiro turno, assim como o atendimento às demandas dos jovens trabalhadores.

O crescimento do número de ginásios e colégios particulares em todos os distritos da cida- 
de demonstra que a criação de instituições de ensino secundário municipal não foi suficiente para suprir a carência de vagas. Por outro lado, as publicações denunciavam a precariedade do funcionamento de unidades escolares públicas secundaristas recém-inauguradas.

O ensino municipal está agora com uma exigência muito engraçada. Não achamos outro adjetivo para o caso. Afinal, nos tempos de hoje nada mais admira. 0 fato é o seguinte: o diretor do ginásio municipal de Bangu está exigindo dos alunos um banco para uso nas aulas, pois o estabelecimento não dispõe de mobiliário. Quem não levar banco, não se matricula. (ALEGRIA..., 1952, p. 5).

A associação dos ex-alunos do 'João Alfredo' que é presidida pelo Coronel Milton atual Diretor da Penitenciária do D.F. há cerca de um mês entregou a um mês ao Prefeito Negrão de Lima, detalhado memorial expondo a situação deplorável que se encontra a tradicional instituição, mas até aqui não foi tomada nenhuma medida para recuperar o estabelecimento. 0 Ginásio João Alfredo está localizado a Avenida 28 de Setembro, 109, não tem instalações sanitárias, nem bebedouros. As telhas em raríssima exceção não se acham quebradas, o que permite quando chove o prédio ficar todo alagado. (PEDEM..., 1956, p. 2).

Os alunos que conquistavam a vaga por meio de concursos disputados, ao iniciar as aulas, se deparavam com muitos problemas: o péssimo estado de conservação dos prédios, a falta de professores, cortes de energia e de água. A luta não terminava quando um ginásio ou colégio público era inaugurado no bairro; ao início de cada ano, pais, responsáveis e alunos tinham que começar uma nova batalha para assegurar condições mínimas para funcionamento da unidade escolar.

\section{Considerações finais}

O jornalista Genolino Amado publicou diariamente, entre 1943 e 1944, em um periódico de grande circulação, "As crônicas do Rio". Nestes textos diários o escritor tenta definir o cotidiano de uma cidade cheia de contrates:
Da Tijuca a Ipanema, em sua viagem distraída, Aníbal Machado viu o drama dos garotos soltos na rua, o drama da mocinha que vem trabalhar na cidade, a tragicomédia dos velhos burocratas que tanto se angustiam com o livro do ponto como com a última batalha da Europa. Viu em cinquenta minutos de passeio, os cinquenta anos de transformação social que se desenrolam da Praça Saenz Pena à Praça General Osório, entre a jovem de Haddock Lobo que ainda estuda piano e girl americanizada de Copacabana que saracoteia ao som do swing rodando na vitrola. (AMADO, 1946, p. 67).

Ao final da década de 1930, o Distrito Federal atraía muitas pessoas. Muitos turistas do Brasil e do mundo chegavam todos os dias, buscando conhecer suas belezas naturais, que lhe deram o título de "Cidade Maravilhosa". Eram muitos os lugares concorridos do Distrito Federal: as praias, o Cristo Redentor, inaugurado em 1931, a Cinelândia e o Teatro Municipal.

Muitos migrantes também são atraídos para o Rio de Janeiro, mas por outros motivos. Afugentados pela seca, nortistas e nordestinos buscavam empregos nas indústrias e na construção civil. Boa parte desses migrantes encontrava serviço na construção civil, as construtoras cresciam, impulsionadas pela especulação dos espaços nos bairros. Foram definidas fronteiras simbólicas: a gare da Central do Brasil e a Avenida Brasil, que separavam os subúrbios do Centro e da zona sul.

Os projetos de vida desenhados pelo Estado aos seus moradores são bem diferentes. A análise dos dados sobre o ensino secundário nas décadas de 1940 e 1950 demonstrou isso. Uma primeira constatação é a falta dos investimentos públicos na construção de escolas secundárias. A Prefeitura do Distrito Federal tinha uma posição clara em relação à escolarização da sua população: deveria se restringir aos ensinos primário e profissionalizante. 0 ensino secundário, destinado a formar uma elite, era considerado pouco útil aos serviços do Estado. É interessante pensar que como uma metrópole, o Distrito Federal concentrava as instituições renomadas do país, como 
o Colégio Pedro II e o Colégio Militar, e isso seria suficiente para construir seus quadros intelectuais. Até 1947, quando foi inaugurado o primeiro ginásio municipal, os cariocas que não pudessem arcar com as mensalidades de instituições particulares encerravam seus estudos após o primário.

A declaração do Secretário de Educação do Distrito Federal deixava clara a intenção de que apenas a iniciativa privada ofereceria o ensino secundário. Neste sentido, o processo de metropolização intensificado nas décadas de 1940 e 1950 determinou quais seriam os bairros que iriam ter ginásios e colégios, pela capacidade de seus moradores de arcar com as mensalidades. Os salários dos trabalhadores não lhes deixavam muitas escolhas: as favelas, uma resistência dos mais pobres em permanecer na zona sul, ou os subúrbios. Ao buscar a moradia própria nesses espaços, os residentes abriam mão de benefícios como escolas, hospitais, bibliotecas, teatros e museus. 0 formato de expansão reforçava as desigualdades socioeconômicas, na medida em que excluía seus moradores, já segregados espacialmente pela distância do Centro e pela rede de transporte precária, de qualquer possibilidade de escolarização secundária. Havia distritos em que não havia nenhuma instituição de ensino secundário. Neste sentido, a organização do território reforçava a desigualdade.

Ainda que os ensinos primário e profissionalizante permanecessem como prioritários para a Prefeitura do Distrito Federal, a partir do final da década de 1940 foram fundados os primeiros ginásios municipais, uma conquista de grupos de moradores organizados que se mobilizaram por maiores oportunidades educacionais. Neste sentido, é importante destacar que a maior parte das unidades escolares públicas de ensino secundário foi aberta nos subúrbios, após campanhas em jornais, passeatas e mobilização política junto aos vereadores. 0 movimento estudantil foi outro fator importante, que fortaleceu as conquistas em prol do ensino secundário público.
A análise da distribuição dos ginásios e colégios pelos distritos cariocas ao final da década de 1950 revela que a expansão de oportunidades de escolarização secundária foi pequena. Neste período, havia distritos populosos sem instituições públicas de ensino secundário como Penha e Jacarepaguá. 0 número de colégios e ginásios particulares era muito maior do que os públicos em todas as regiões da cidade. Houve aumento muito maior das instituições privadas do que públicas. Neste sentido, é interessante notar que os mantenedores criaram estratégias para se instalar nos bairros mais pobres, construindo prédios mais simples, com menos recursos e diminuindo o salário dos professores. Por outro lado, o crescimento do número de ginásios particulares demonstra que a Prefeitura estava longe de atender à demanda da população por escolarização neste nível de ensino. Os suburbanos e os moradores pobres da zona sul que conseguiam permanecer na escola após a conclusão do ensino primário continuaram enfrentando dificuldades para pagar as mensalidades de colégios próximos às suas residências, mas distantes das suas realidades econômicas. Para os que prestavam disputados concursos, a luta não se encerrava com a matrícula; a cada início de ano letivo a mobilização era permanente para assegurar as condições mínimas para o início das aulas.

\section{REFERÊNCIAS}

A SITUAÇÃO do ensino secundário no Distrito Federal. A Noite, Rio de Janeiro, p. 4, 27 maio 1935.

ACABOU o Presidente com os excedentes do Colégio Pedro II. A Noite, Rio de Janeiro, p. 2, 27 mar. 1957.

ALEGRIA dos carpinteiros. Diário Carioca, Rio de Janeiro, p. 5, 30 mar. 1952.

AMADO, Genolino. Inocentes do Leblon. Rio de Janeiro: Livraria do Globo, 1946.

APARTAMEnTOS. Correio da Manhã, Rio de Janeiro, p. 18, 26 maio 1946.

BARRETO, L. Clara dos Anjos. São Paulo: Cia das Letras, 2012. 
BRASIL. Câmara dos Deputados. Decreto no 19.890, de 18 de abril de 1931. Dispõe sobre a organização do ensino secundário. In: BRASIL. Coleção das Leis de 1931. Atos do Governo Provisório: Decretos de janeiro a abril. Rio de Janeiro: Imprensa Nacional, 1942. v. 1. p. 470-482. Disponível em: https:// www2.camara.leg.br/atividade-legislativa/ legislacao/colecao-anual-de-leis/colecao5.html. Acesso em: 30 mar. 2020.

BRASIL. Decreto no 21.241, de 04 de abril de 1932. Consolida as disposições sobre a organização do ensino secundário e dá outras providências. In: BRASIL. Coleção das Leis da República dos Estados Unidos do Brasil de 1932. Atos do Governo Provisório (janeiro a março). Rio de Janeiro: Imprensa Nacional, 1932. v. 1. p. 11-32. Disponível em: https://www2.camara.leg.br/ atividade-legislativa/legislacao/colecao-anual-deleis/colecao5.html. Acesso em: 30 mar. 2020.

BRASIL. Decreto-lei n ${ }^{\circ} .244$, de 9 de abril de 1942. Lei orgânica do ensino secundário. In: BRASIL. Coleção das Leis de 1942: Atos do Poder Executivo (Decretos-Leis de Janeiro a Março). Rio de Janeiro: Imprensa Nacional, 1942b. p. 20-37. Disponível em: https://www2.camara.leg.br/atividadelegislativa/legislacao/colecao-anual-de-leis/ colecao6.html. Acesso em: 31 mar. 2020.

BOURDIEU, P. Efeitos de lugar. In: BOURDIEU, P. (coord). A miséria do mundo. Petrópolis, RJ: Vozes, 1997.

BUENO FILHO, Luiz. Novos problemas em Osvaldo Cruz. Correio da Manhã, Rio de Janeiro, p. 1, 16 mar. 1952.

CANDIDATOS em profusão. Rio de Janeiro, A Manhã, p. 8, 10 fev. 1951.

COLÉGIO PEDRO II. Anuário do Colégio Pedro II. Vol. XVI (1951-1961). Rio de Janeiro, 1963.

CONTINUA sem professores. Diário de Notícias, Rio de Janeiro, p. 2, 22 jun. 1946.

COPACABANA. Correio da Manhã, Rio de Janeiro, p. 18, 26 maio 1946.

DISTRITO FEDERAL. Decreto Municipal no 8.976, de 16 de outubro de 1947. Rio de Janeiro, 1947.

DISTRITO FEDERAL. Anuário Estatístico do Distrito Federal 1951/1955. Ano XVII. Rio de Janeiro, 1956.

EDIFÍCIO Gotin Maclair. Correio da Manhã, Rio de Janeiro, p. 10, 02 set. 1952.
FREITAG, B. Capitais migrantes e poderes peregrinos: o caso do Rio de Janeiro. Rio de Janeiro: Papirus, 2009.

FUNDAÇÃO GETÚLIO VARGAS (FGV). CPDOC. Arquivo Gustavo Capanema G C 35. 10.18/1, pasta V - 11, série g. Rio de Janeiro, 2019.

HÁ TRÊS anos em demanda judicial. Correio da Manhã, Rio de Janeiro, p. 4, 02 set. 1956.

INICIA-SE a mais ampla reforma educacional do Distrito Federal. 0 Radical, Rio de Janeiro, p. 13, 24 nov. 1940.

INSTITUTO BRASILEIRO DE GEOGRAFIA E ESTATÍSTICA (IBGE). Censo Demográfico de 1960. Disponível em: https://biblioteca.ibge. gov.br/visualizacao/periodicos/68/cd_1960_v1_ br.pdf. Acesso em: 30 mar. 2020.

INSTITUTO Juruena. Gazeta de Notícias, Rio de Janeiro, p. 6, 06 mar1940.

LISSOVSKY, Maurício; SÁ, Paulo Sérgio Moraes. 0 novo em construção: o edifício-sede do Ministério da Educação e Saúde e a disputa do espaço arquiteturável nos anos 1930. In: GOMES, Ângela de Castro. Capanema: o ministro e seu ministério. Rio de Janeiro: Editora FGV, 2000. p. 49-71.

LOURENÇO FILHO, Manoel. Alguns elementos para o estudo dos problemas do ensino secundário. Revista Brasileira de Estudos Pedagógicos, v. XIV, n. 40, set./dez. 1950.

LUCHMANN, Lígia Helena Hann. Associações, participação e representação: combinações e tensões. Lua Nova, São Paulo, n. 84, p. 352-364, 2011.

MAGALHÃES, Sérgio; IZAGA, Fabiana; PINTO, A. Cidades: mobilidade, habitação e escala: um chamado à ação. Brasília, DF: Confederação Nacional da Indústria (CNI), 2012. Disponível em: http:// www.portaldaindustria.com.br/cni/publicacoeseestatisticas/publicacoes/2012/09/1,5580/ cidades-mobilidade-habitacao-e-escala-umchamado-aacao.html. Acesso em: 10 fev. 2020.

MAIS DE duas mil vagas nas novas seções do Pedro II. A Manhã, Rio de Janeiro, p. 2, 07 fev. 1952.

MAIS FÁCIL a compra da casa própria com os financiamentos do pós-guerra. Diário Carioca, Rio de Janeiro, p. 5, 15 jan. 1953.

MANIFESTO da União Carioca dos Estudantes Secundários. Correio da Manhã, Rio de Janeiro, p. 8, 28 mar. 1953. 
MARECHAL Hermes terá um ginásio municipal. Diário Carioca, Rio de Janeiro, p. 8, 07 out. 1951.

MASSUNAGA, Magda Rigaud Pantoja. 0 Colégio Pedro II e o Ensino Secundário Brasileiro: 19301961. 1989. Dissertação (Mestrado em Educação) - Universidade Federal do Rio de Janeiro (UFRJ), Rio de Janeiro, 1989.

MIYASAKA, C. R. Os trabalhadores e a cidade: a experiência dos suburbanos cariocas (18901920). 2016. 328 f. Tese (Doutorado em História) - Instituto de Filosofia e Ciências Humanas, Universidade Estadual de Campinas (Unicamp), Campinas, SP, 2016.

MOTTA, M. Rio, cidade-capital. Rio de Janeiro: Jorge Zahar, 2004.

NÃO HÁ razões para aflições. 0 Radical, Rio de Janeiro, p. 2, 23 nov. 1940.

NO EnSINO. A Manhã, Rio de janeiro, p. 4, 08 maio1951.

NUNES, Brasilmar Ferreira; MOURA, Heitor Vianna. Imaginário urbano e conjuntura no Rio de Janeiro. URBE - Revista Brasileira de Gestão Urbana, v. 5, n. 1, p. 91-105, jan./jun. 2013.

OLIVEIRA, Antonio; LOBO, Eulália Maria Lahmeyer. O Estado Novo e o sindicato corporativista 19371945. In: LOBO, Eulália Maria Lahmeyer (org.). Rio Janeiro operário: natureza do Estado, a conjuntura econômica, condições de vida e consciência de classe 1930-1970. Rio de Janeiro: Acess, 1992. p. 102-193.

PEDEM em memorial a Negrão que seja recuperado J. Alfredo. Diário Carioca, Rio de Janeiro, p. 2, 20 nov. 1956.

PRÉDIO NA Tijuca. Correio da Manhã, Rio de Janeiro, p. 13, 17 maio 1942.
PRÉDIO PARA colégio. Correio da Manhã, Rio de Janeiro, p. 12, 27 maio 1942.

REORGANIZAÇÃo do ensino. Correio da Manhã, Rio de Janeiro, p. 2, 17 out. 1947.

RESTABELECIDO o ensino industrial nos educandários da Prefeitura. Diário de Notícias, Rio de Janeiro, p. 4, 20 out. 1954.

REVISTA BRASILEIRA DE ESTUDOS PEDAGÓGICOS. Rio de Janeiro, v. 6, n. 16, out. 1945.

SCHWARCZ, Lília Moritz. Da minha janela vejo o mundo passar: Lima Barreto, o centro e os subúrbios. Estudos Avançados, São Paulo, v. 31, n. 91, p. 123-142, set./dez. 2017.

SEM ESCOLA secundária. O Imparcial, Rio de Janeiro, p. 2, 05 out. 1941 .

SEVCENKO, Nicolau. O prelúdio republicano, astúcias da ordem e ilusões do progresso. In: SEVCENKO, Nicolau (org.). História da vida privada no Brasil. São Paulo: Companhia das Letras, 1998. p. 7-48.

SILVA, Geraldo Bastos. A educação secundária: perspectiva histórica e teoria. São Paulo: Companhia Editora Nacional, 1969.

TORRES, Pedro Henrique Campello. Avenida Brasil - tudo passa quem não viu. Formação e ocupação do subúrbio rodoviário no Rio de Janeiro. Revista Brasileira de Estudos Urbanos, São Paulo, v. 20, n. 2, p. 287-303, maio/ago. 2018.

TREM para Santa Cruz. Diário de Notícias, Rio de Janeiro, p. 5, 04 jun. 1947.

Recebido em: $14 / 04 / 2020$

Aprovado em: 24/08/2020

(cc) EY-No Este é um artigo publicado em acesso aberto sob uma licença Creative Commons. 